\title{
Drivers and Barriers to Adopt E-SCM in Jordanian SMEs
}

\author{
YaserJebril Almatarneh ${ }^{1}$, Jamal A. Farooqui ${ }^{2}$ \\ Research Scholar Aligarh Muslim University (Amu) Aligarh, 202001 \\ Professor Aligarh Muslim University (Amu) Aligarh, 202001
}

\begin{abstract}
The purpose of this paper is to determine the drivers and barriers of adopting electronic supply chain management (E-SCM) practices in small and medium scale enterprises (SMEs) in Jordan. The methodology is based on critical review of research papers and analyzing the data acquired from the sample of the study through constructed survey. As per the primary data analysis, the quantitative data from the selected pool of SMEs from Jordan showed that Lack of qualified staff and skills, Resistance to change, Security and Perceived cost are the major barriers in adopting the technology of E-SCM in order to ease the working of business organizations. Further, the primary analysis of the study revealed that the primary factors acting as the drivers for introducing the E-SCM systems in SMEs are perceived usefulness, customer pressure, supplier pressure, competitor pressure, top management support, absorptive capacity and government support. The findings contribute to help the decision makers in public and private sector in understanding the key factors which inhabit or encourage SMEs in Jordan to adopt E-SCM.
\end{abstract}

Keywords: Electronic Supply Chain Management, SMEs, Jordan

\section{Introduction}

In the past decade the combination of market, economic, and technology forces like increase in supply networks combination, globalization, and product variety proliferation has initiated the companies to examine and try to recreate the strategies of supply chain (Hakikur, 2011). The rapid increase in uncertainty in the evolution of market has made the companies aware about supply chains. Organizations that have learned about building as well as contributing into supply chains will definitely get the competitive advantage in the market (Chong and Choi, 2010).

E-SCM is a collaborative use of technology to improve the operations of supply chain activities as well as the management of supply chains (Turban et al., 2011). Lankford (2004) defined E-SCM as a combination and balance of the Internet and the supply chain management. The use of Information Technology in the past decade has helped in transforming the ways in which the companies are conducting their entire business process.

According to Graham and Folinas (2013), SMEs require making large investments and sharing the efficient information for the purpose of adopting the practices of e-business in the business. Moreover, they also require building the relations for long period with the trading partners.

The increasing need of effective SCM to the SMEs to succeed and be able to compete in the market forced them to create close relationships with their business partners. The basis of competition between organizations is shifting to how effectively these supply chains are managed. Successful SCM requires the recognition that the firm is simply one player in the long chain, and requires a high level of information sharing and collaboration with other members (Sahay, 2003).

The present study intends to conclude the research study on the practices of electronic supply chain management (E-SCM) among Small and Medium Enterprises (SMEs) at Jordan. The purpose was also to list the factors that might act as a hindrance towards adaptation of E-SCM technology, factors that are the enablers of the adoption of E-SCM. The study assumed some factors based on the existing literature, explaining the adoption and non-adoption of E-SCM, regarded as barriers or drivers. An inductive approach has been applied using the quantitative data collected through the primary data collection method. the primary data is collected from SMEs in Amman, Aqaba, and Zarqa using structured questionnaires for the target population of the study. The obtained data was then analyzed for the exploratory factors taken under the study, using statistical techniques through SPSS 21.0.

\section{Literature}

An important driver for adopting of E-SCM is the absorptive capacity (ACAP) defined by (kedia and lewin, 1998) as firm's receptivity to technological change. (Cohen and levinthai, 1990) defined it as firm's ability to value, assimilate, and apply new knowledge. The firm could pay the cost of knowledge acquisition without gaining the benefits of exploitation (Lane et al., 2006). Failures in past knowledge exploration with partners can impede assimilation and intra firm knowledge transference (Saenz et al., 2014). 
Perceived benefits of E-SCM is an another important factor, Based on the empirical study of 104 retail stores of UK by Eng (2004) who highlighted the perceived usefulness of E-SCM through focusing on the role of e-marketplaces on the supply chain. Graduating to E-SCM can help the firms to internationalize and also get access to international channel partners easily. Further, E-SCM will have a reduced cost, better efficiency and rationalized operations. This will be because of better communication and prompt exchange of information via internet.

Perceived Ease of Use of E-SCM is also founded as another important driver to adopt E-SCM in the firms. White and Plant, (2014) investigated the challenges of adoption of e-commerce for the SCM in developing economy of Nigeria through a study of SMEs. It was observed that there is a considerable association between the perceived ease of use of e-commerce technology and its acceptance.

One of the critical factors for adoption of E-SCM is government policies and the infrastructural offerings that provide the requisite impetus to the companies to upgrade to E-SCM which is an uphill task if government is unsupportive. The firms need a strong support from government when it comes to import of resources or finished goods from other countries or even from within the country. The government policies include policies, procedures, rules and regulations pertaining to the supply chain management. The adoption of E-SCM is often subjective to the encouragement and supportive infrastructure to boost exports by elevating the level of competitiveness of the manufacturing sector in the globalized market through the augmentation of the logistics and supply chain capacities. Government needs to make efforts to increase international trade for not only selling finished goods but also for gaining raw materials from other nations. Also, government must make considerable efforts to overcome hindrances like language barriers, transition and associated costs, currency exchange rates, tariffs and administrative initiatives (Quesada et al, 2012).

The lead firm experiences a lot of pressure from the suppliers for adoption of E-SCM. Seuringand Müller (2008) explored the pressure of suppliers based on the power-dependency theory that proposes that there is power in the capacity of one party to exert pressure to make the other party perform as per its wishes. In case of business, such power is gained by the volume of sales or profitability generated by the powerful party for the other party.

Another vital factor that drives the adoption of E-SCM can be the pressure from the customers. Customers who prefer online shopping and want globalized shopping experience exert pressure on the firms to adopt E-SCM which is an inevitable aspect of the e-commerce. Lee (2006) asserted that customers are getting highly demanding due the rise in globalization and access to information. The customers of today are hard to convince and satisfy, thus companies have to strive to achieve excellence in business and this is possible through process augmentation. Quayle (2005) posits that the pressure of major customers is more for adoption of E-SCM especially in the cases of B2B market format.

Top management support is predictor of E-SCM adoption decision by firms (Lin, 2014). Rutherford and Lin (2007) studied the impact of managers' demographic factors on E-SCM adoption in American SMEs and the results showed that managerial support plays an important role in the adopting and applying stages. Wojitkowski and Hardesty (2001) suggested that, for the successful adoption of e-commerce technologies, the manager should have a working knowledge of the new technology. SMEs managers with a good knowledge, positive attitude toward IT, who is innovative, risk taking, entrepreneurial, are more likely to adopt IT (AlQirim, 2007). Managerial support is required in the electronic business environment as the management of supply chain deals with various issues like globalization, sharing of information etc. which is not possible through the proper support by the top management of the organization (Al-zu'bi, 2010).

Resistance to change during adaptation and implementation process was considered by Bayraktar et al (2009) as the fundamental factor which prevents companies to take benefits of E-SCM as enterprises implement new system such as ERP which needs reengineering process that requires employees to change the normal operating practices to tune with ERP practices, this required change is very difficult for employees have been working for a long time which negatively influence the operations performance. Human resistance to change is one of the main hindrances in the implementation of e-supply chain systems (Trkman and Groznik, 2006).

Ratnasingam (2004) studies the SMEs with an attempt to identify the perceived barriers and risks of ecommerce supply chain management amongst the SMEs of Australia and New Zealand. It was deduced that SMEs have restricted power in their respective supply chain networks as they have access to limited resources and capital to put in advanced technology essential for E-SCM.

Elahi (2009) argued that areas of supply chain which need security attention are proposed in e-supply chain information security framework. This will further be considered as a guideline for managers to find out if their e-supply chain network is secured enough. The research has proposed an approach where a smartcard will be utilized to provide transparent authentication of the user from his device. This approach deletes any inconvenience for the user in having to remember username and password information for each service hence providing the opportunity to improve the level of security through using asymmetric cryptography. It has been concluded that IT has had great influence in obtaining an effective SC and going toward E-SCM. 
One of the reasons being perceived by the organization for non-adoption of e-technologies is the cost concern. It is necessary for the other firms along the supply chain to realize the benefits of e-Commerce technologies and that they are not mere investment but they will the benefits for incurring this additional cost.

Jordan private economy is mainly comprises of SMEs that presents around $99.6 \%$ of overall companies that are outside the agricultural sectors (Sami, 2012). In context of employment, the formal SMEs play important role in jobs creation, as they give employment to around $71.4 \%$ people in the private sector and around $49.4 \%$ in the both the private and public sector of the country (Bakri, 2013). There are 165,879 registered enterprises in the Kingdom (department of statistics, establishment census 2011).

The definition of SMEs issued on Sep 2015 by the government, biasing the amount of employees and registered capital (Jordanian Young Economists Society, 2015) classification of MSMEs is given in Table 1 below.

Table 1: Classification of MSMEs in Jordan (Jordanian Young Economists Society, 2015)

\begin{tabular}{|l|l|l|}
\hline Classification & Capital Investment (JD) & No. of Employees \\
\hline Micro & Less than 30,000 & $1-9$ \\
\hline Small & Above 30,000 & $10-49$ \\
\hline Medium & Above 30,000 & $50-249$ \\
\hline Large & Above 30,000 d above \\
\hline
\end{tabular}

\section{Methodology}

The objective of the study is to identify drivers and barriers affecting the E-SCM adoption in Jordanian SMEs. In the light of objective of the study, an exploratory-cum-descriptive research design has been considered suitable for the study. Initially based on literature review, an exploratory analysis of E-SCM was conducted to identify key factors of E-SCM adoption and the descriptive research design adopted to provide a comprehensive and detailed explanation of the adoption of E-SCM in the SMEs in Jordan. The findings of the study are expected to provide greater insights and newer facts. For the current study, the researcher has used a structured questionnaire. The questionnaire consists of mostly close-ended questions wherein Likert-scale has been used for the responses from the selected sample of respondents. The questionnaire has been divided into two sections A and B. Section A (Qs. 1-5) the first two questions are meant to get details on number of employees and investment which will help to categorize the companies to micro, small, or medium enterprisers by comparing with the actual proportion of SMEs in Jordan. The third question is closed end question with four options to get information about the experience of the firm. The fourth question is a closed end question with seven options seeks knowledge about IT infrastructure which influences E-SCM at various levels in the firm.

Section B contains questions related to drivers and barriers of E-SCM. 49 items were extracted to measure the drivers and barriers of adoption of ESC in the firms. Drivers to E-SCM were measured using a five point rating scale ( 1 strongly disagree, 2 disagree, 3 neutral, 4 agree, 5 strongly agree). The purpose of this part is to identify the influence of each driver on the adoption decision in SMEs. All statements were adapted from studies by $\mathrm{Wu}$ and Chuang (2010), Tarofder et al (2013), Chang and Tsia (2006), Hefu lie (2010), Jeffrey (2009), Olatokun and Bankole (2011), and Fang et al (2003). Barriers to E-SCM were measured using a five point rating scale ( 1 strongly disagree, 2 disagree, 3 neutral, 4 agree, 5 strongly agree). The purpose of this part is to identify the influence of each barrier on the adoption decision in SMEs in India and Jordan. All statements are already tested by Harland et al (2007), Fawcettet et al (2008), Damaskopoulos and Evgeniou (2003), Patterson et al (2003), Wu and Chuang (2010), and Hefu lie (2010). The target population of the study includes SMEs which don't adopt electronic supply chain management (E-SCM) in Amman, Aqaba, and Zarqa. The sampling technique of convenience method has been used for the study. The questionnaire administration was done by approaching each of the companies' offices through e-mails, and visits to their companies requesting them for permission to conduct surveys in their respective organizations. The researcher obtained their due consent and then sent the questionnaires via e-mail, others filled the questionnaire online, and written questionnaires were delivered in hand to the sample respondents requesting for completion and submission of the filled questionnaires.

\section{Data Analysis}

\section{Respondents' Profile}

Out of 134 respondents reached, only 93 respondents are found useful for analysis. To determine the firm size the classification of SMEs in Jordan depends on the number of employees. The first question in the questionnaire seeks the firm size of the respondents. Any responses couldn't meet the criteria of SMEs were omitted from the final analysis. Table 2 below shows the number of small and medium firms and their experience in the market. 
Table 2: Respondents' Profile

\begin{tabular}{|c|c|c|c|c|c|}
\hline \multirow[t]{2}{*}{ Firm Size } & \multirow{2}{*}{ No. of firms } & \multicolumn{4}{|c|}{ Experience in years } \\
\hline & & $<5$ & $5-10$ & $11-15$ & $>15$ \\
\hline Medium & 52 & 11 & 16 & 14 & 11 \\
\hline
\end{tabular}

Table 3: IT Components

\begin{tabular}{|l|c|}
\hline \multicolumn{1}{|c|}{ IT Components } & Frequency \\
\hline Computer hardware platforms & $90.3 \%$ \\
\hline Networking and telecommunications platforms & $10.8 \%$ \\
\hline Enterprise software applications & $15.1 \%$ \\
\hline Database management & $24.9 \%$ \\
\hline Internet platforms & $83.9 \%$ \\
\hline Operating system platforms & $23.7 \%$ \\
\hline
\end{tabular}

Table 3 above shows the frequency of IT components available within the firms under the study.

\section{Drivers to E-SCM Adoption}

33 items were asked to the respondents regarding drivers to adopt E-SCM practices. For reducing the items of drivers into a manageable number of factors, the researcher conducted factor analysis. The relevance of a variable is determined when it fits into one of the identified factors. Table 4 below shows that the Chi-square value is 3570.634 at a significance of $p$-value $=.000$; which is less than .05 . Also, the correlation matrix is not an identity matrix. This means that there are relationships or patterns between the variables.

Table 4: KMO and Bartlett's Test Results

\begin{tabular}{|l|c|c|}
\hline \multicolumn{2}{|c|}{ KMO and Bartlett's Test } & .843 \\
\hline Kaiser-Meyer-Olkin Measure of Sampling Adequacy. & Approx. Chi-Square & 3570.634 \\
\cline { 2 - 3 } Bartlett's Test of Sphericity & Df & 528 \\
\cline { 2 - 3 } & Sig. & .000 \\
\hline
\end{tabular}

The researcher used the orthogonal/Varimax rotation as the criterion to conduct factor analysis for drivers which has led to a clear identification of seven different drivers as shown in table 5.

Table 5: Results of Factor Analysis for Drivers

\begin{tabular}{|c|c|c|c|}
\hline Factor & Variables & Factor Loading & Cronbach's Alpha $\alpha$ \\
\hline \multirow{7}{*}{ PerceivedUsefulness (PU) } & Increasing sale revenue. & 0.775 & \multirow{7}{*}{0.901} \\
\hline & Expanding markets for existing products or services. & 0.789 & \\
\hline & Improving coordination with suppliers and customers. & 0.833 & \\
\hline & Generating competitive advantage. & 0.835 & \\
\hline & Improve the quality of work. & 0.842 & \\
\hline & Reduce overall cost. & 0.843 & \\
\hline & Increase customer satisfaction. & 0.856 & \\
\hline \multirow{6}{*}{ Customer Pressure (CP) } & $\begin{array}{l}\text { Your major customers demand that you should establish } \\
\text { strong e-business relationships with them. }\end{array}$ & .715 & \multirow{6}{*}{0.904} \\
\hline & $\begin{array}{l}\text { Main customers that matter to you believe that your firm } \\
\text { should use E-SCM. }\end{array}$ & .729 & \\
\hline & $\begin{array}{l}\text { Your firm may not retain its important customers without } \\
\text { E-SCM }\end{array}$ & .766 & \\
\hline & $\begin{array}{l}\text { Many of your customers are keen that your firm should } \\
\text { implement E-SCM practices. }\end{array}$ & .773 & \\
\hline & $\begin{array}{l}\text { your relationship with your major customers may suffer } \\
\text { if you don't implement E-SCM }\end{array}$ & .802 & \\
\hline & $\begin{array}{l}\text { Your customers may consider you as backward if you do } \\
\text { not implement E-SCM }\end{array}$ & .808 & \\
\hline \multirow{4}{*}{ Supplier Pressure (SP) } & $\begin{array}{l}\text { Suppliers request directly link up to our databases (e.g., } \\
\text { via Enterprise Resource Planning/ERP systems) }\end{array}$ & .816 & \multirow{4}{*}{0.855} \\
\hline & $\begin{array}{l}\text { Main suppliers that matter to you believe that you should } \\
\text { use E-SCM. }\end{array}$ & .869 & \\
\hline & $\begin{array}{l}\text { We may not retain our important suppliers without E- } \\
\text { SCM. }\end{array}$ & .891 & \\
\hline & $\begin{array}{l}\text { E-SCM has been widely adopted by our suppliers } \\
\text { currently. }\end{array}$ & .907 & \\
\hline Competitor Pressure (COP) & $\begin{array}{l}\text { E-SCM has been widely adopted by your competitors } \\
\text { currently. }\end{array}$ & .793 & 0.918 \\
\hline
\end{tabular}


Drivers and Barriers to Adopt E-Scm in Jordanian Smes

\begin{tabular}{|c|c|c|c|}
\hline & $\begin{array}{l}\text { Your main competitors that have adopted E-SCM } \\
\text { benefited greatly. }\end{array}$ & .836 & \\
\hline & $\begin{array}{l}\text { Your main competitors that have adopted E-SCM are } \\
\text { perceived favorably by customers. }\end{array}$ & .865 & \\
\hline & $\begin{array}{l}\text { Your main competitors that have adopted E-SCM are } \\
\text { more competitive. }\end{array}$ & .879 & \\
\hline \multirow{4}{*}{ Absorptive Capacity (ACP) } & $\begin{array}{l}\text { Your firm has rich information on the state-of-art of E- } \\
\text { SCM. }\end{array}$ & .785 & \multirow{4}{*}{.878} \\
\hline & $\begin{array}{l}\text { Your firm has a clear division of roles and responsibilities } \\
\text { to implement E-SCM. }\end{array}$ & .827 & \\
\hline & $\begin{array}{l}\text { Your firm has the necessary knowledge to learn and } \\
\text { implement E-SCM. }\end{array}$ & .846 & \\
\hline & Your firm has the competences to implement E-SCM. & .877 & \\
\hline \multirow{4}{*}{ Top Management Support (TMS) } & $\begin{array}{l}\text { Top management is aware of the benefits E-SCM for } \\
\text { future success of firm. }\end{array}$ & .574 & \multirow{4}{*}{.747} \\
\hline & $\begin{array}{l}\text { Top management has a vision to project in your } \\
\text { company as a leader in the promotion of E-SCM. }\end{array}$ & .630 & \\
\hline & $\begin{array}{l}\text { Top management has allocated adequate financial and } \\
\text { other resources for the development and operation of E- } \\
\text { SCM. }\end{array}$ & .673 & \\
\hline & Top management is highly interested in using E-SCM. & .774 & \\
\hline \multirow{4}{*}{ Government Support (GS) } & Government supports firms to adopt E-SCM & .603 & \multirow{4}{*}{.815} \\
\hline & $\begin{array}{l}\text { Government's laws protect firms against fraud and web } \\
\text { crimes. }\end{array}$ & .616 & \\
\hline & Government has high responsiveness online & .676 & \\
\hline & Government's forms available to enterprises on the web & .789 & \\
\hline
\end{tabular}

It can be seen in Table 5 that variables are clubbed together to form 7 groups. The variables within each group have high correlations with each other, leading to such clubbing. These seven groups are the seven factors that act as drivers to E-SCM adoption in enterprises named as:

Perceived Usefulness (PU): this factor is a group of 7 variables which reflects the perceived benefits of adopting E-SCM in the firms. The 7 variables have got an internal consistency of 0.823 .

Customer Pressure (CP): 6 variables were grouped together to form this factor with internal consistency 0.927.

Supplier Pressure (SP): 4 variables constitute this factor with internal consistency of 0.805 .

Competitor Pressure (COP) this driver consists of 4 variables with internal consistency .830 .

Absorptive Capacity (ACP): this factor with 4 variables grouped together to form it with internal consistency 0.878

Top Management Support (TMS): this factor deals with 4 variables with internal consistency of 0.747 .

Government Support (GS). Another important driver is the government support to the firms to adopt E-SCM. This driver with 4 variables has got internal consistency of 0.815 .

Table 6: Group Statistics of Drivers

\begin{tabular}{|l|c|c|c|}
\hline \multicolumn{1}{|c|}{ Factor } & N & Mean & Std. Deviation \\
\hline Perceived Usefulness & 93 & 2.6221 & .51622 \\
\hline Customer Pressure & 93 & 3.8495 & .46174 \\
\hline Supplier Pressure & 93 & 2.6935 & .64808 \\
\hline Competitor Pressure & 93 & 3.9651 & .61303 \\
\hline Top Management Support & 93 & 3.8011 & .45078 \\
\hline Absorptive Capacity & 93 & 2.1237 & .43399 \\
\hline Government Support & 93 & 3.4570 & .52856 \\
\hline
\end{tabular}

It's noted from table 6 that the mean value is more than 3 for Customer Pressure, Competitor Pressure, Top Management Support, and Government Support, which indicates that these factors are impactful for adopting E-SCM in SMEs. While the mean value of Perceived Usefulness, Supplier Pressure, and Absorptive Capacity is low(less than 3). Which indicate that these factors are not important in adopting E-SCM in Jordanian SMEs. 


\section{Barriers to E-SCM Adoption}

Based on the literature, 21 items were identified for the barriers. For reducing the items of barriers into a manageable number of factors, the researcher conducted factor analysis. The relevance of a variable is determined when it fits into one of the identified factors.

Table 7: KMO and Bartlett's Test Results

\begin{tabular}{|c|c|c|}
\hline \multicolumn{3}{|l|}{ KMO and Bartlett's Test } \\
\hline \multicolumn{2}{|c|}{ Kaiser-Meyer-Olkin Measure of Sampling Adequacy. } & .862 \\
\hline \multirow{3}{*}{ Bartlett's Test of Sphericity } & Approx. Chi-Square & 2185.691 \\
\hline & Df & 120 \\
\hline & Sig. & .000 \\
\hline
\end{tabular}

KMO measure is equal to .862; which is acceptable. Thus, it can be said that conducting factors analysis is appropriate for this dataset for barriers.

Table 8: Results of Factor Analysis for Barriers

\begin{tabular}{|c|c|c|c|}
\hline Factor & Variables & Factor Loading & Cronbach'sAlpha $\alpha$ \\
\hline \multirow{4}{*}{$\begin{array}{l}\text { Lack of qualified staff and } \\
\text { skills (LSS) }\end{array}$} & Lack of IT skills to implementing E-SCM & .619 & \multirow{4}{*}{0.855} \\
\hline & Lack of computer skills that help implementing E-SCM & .710 & \\
\hline & insufficient training for employees on E-SCM & .718 & \\
\hline & Lack of qualified staff to implement E-SCM practices & .801 & \\
\hline \multirow{4}{*}{ Perceived cost (PC) } & Lead time to install E-SCM is relatively long. & .820 & \multirow{4}{*}{0.901} \\
\hline & Costs of information sharing is relatively high & .836 & \\
\hline & $\begin{array}{l}\text { Lead time to complete training before starting to use E-SCM is } \\
\text { long }\end{array}$ & .887 & \\
\hline & E-SCM has high setup costs. & .908 & \\
\hline \multirow{4}{*}{ Resistance to Change (RC) } & Adopting E-SCM requires Altering Organizational Structures & .712 & \multirow{4}{*}{0.904} \\
\hline & Adopting E-SCM requires Changing the Firm's Strategic Direction & .847 & \\
\hline & Adopting E-SCM requires Changing Systems and Work Processes & .878 & \\
\hline & Adopting E-SCM requires Changing Technology/IT & .910 & \\
\hline \multirow{4}{*}{ Security (SC) } & $\begin{array}{l}\text { Security in the process (Data transmission to the wrong person, } \\
\text { data theft). }\end{array}$ & .850 & \multirow{4}{*}{0.918} \\
\hline & Data can be altered or destroyed in an unauthorized manner. & .866 & \\
\hline & Hackers, Viruses, and malicious applications attack. & .877 & \\
\hline & $\begin{array}{l}\text { Timely and reliable access to data and information services for } \\
\text { authorized users. }\end{array}$ & .887 & \\
\hline
\end{tabular}

Table 8 clearly shows extraction of four barrier factors. These factors are named as lack of qualified staff and skills (LSS), security (S), resistance to change (RC) and perceived cost (PC).

Lack of Qualified Staff and Skills (LSS): this factor consists of 4 variables with internal consistency of 0.855

Perceived Cost (PC): 4 variables with internal consistency 0.901 form this factor. Resistance to Change (RC): 4 variables were loaded under this factor with internal consistency 0.904

Security (SC): 4 variables were grouped to this factor with internal consistency 0.918 .

Table 9: Group Statistics of Barriers

\begin{tabular}{|l|c|c|c|}
\hline \multicolumn{1}{|c|}{ Factor } & N & Mean & Std. Deviation \\
\hline Perceived Cost & 93 & 3.5538 & .72873 \\
\hline Lack of Qualified Staff and Skills & 93 & 3.8172 & .70916 \\
\hline Security & 93 & 2.8925 & .58560 \\
\hline Resistance to Change & 93 & 3.5645 & .44676 \\
\hline
\end{tabular}

It's noted from table 9 that the mean value is more than 3 for perceived cost, lack of qualified staff and skills, and resistance to change, which indicates that these factors are impactful for adopting E-SCM in SMEs. While the mean value of security is low(less than 3) which indicates that security concerns is not an important factor in adopting E-SCM in Jordanian SMEs

\section{Conclusions}

Barriers: As per the primary data analysis, the quantitative data from the selected pool of SMEs from Jordan showed that Lack of qualified staff and skills, Resistance to change, Security and Perceived cost are the major barriers in adopting the technology of E-SCM in order to ease the working of business organizations. Further the statistics reveal that the barriers of 'Lack of qualified staff and skills', 'Perceived cost', and 'Resistance to change' are more impactful against E-SCM adoption in Jordan than the barrier of 'Security'.

SMEs in Jordan comprises of working staff having inadequate technical or web-specific skills, thereby being unable to practice any changes in the technological view, which itself lead to resistance to changes. The foremost problem arises because of lack of training facilities and IT skills among the employees. Because adopting E-SCM is not merely a rule, rather a set of changes that demands rearrangement and reengineering in 
the operating systems followed by staff, proper training facilities with impartation of necessary IT skill are preliminary to the successful adoption of E-SCM.

Drivers: For the enablers of technology, the primary analysis of the study revealed that the primary factors acting as the drivers for introducing the E-SCM systems in SMEs are perceived usefulness, customer pressure, supplier pressure, competitor pressure, top management support, absorptive capacity and government support. The statistics determined that the factors under the drivers 'Customer pressure', 'Supplier pressure', 'Competitor pressure','Top management support', and 'Government support' showed more concentration in the SMEs for Jordan And for the remaining drivers 'Perceived Usefulness' , and 'Absorptive capacity' were regarded as lesser prevalent factors for Jordanian SMEs.

The analysis held duly assist the existing research on the positive association between top management level knowledge of ICT, absorptive capacity and investment level in IT, thus confirming as a key growth factor in adoption of E-SCM technology (Wojitkowski and Hardesty, 2001). Customer satisfaction, on the other hand are among the main objectives of any enterprise, thus encourage the implementation of competent business environment. As per the existing cases, E-SCM helps in gaining customer satisfaction by providing them with high quality products at relatively low cost through highly supple and efficient distribution. Collaboration among trading partners help in attaining the excellent quality deliverable to the customers (Chou et al, 2004). Pressure to build and maintain customer and supplier relationship therefore propels the organization to adopt ESCM, in order to provide a diligent system of serving quickly and effectively.

\section{Recommendations}

The electronic supply management systems effectively integrate suppliers, customers, manufacture and logistics services on one platform; improve performances of small scale enterprises by successively reducing multiple tasking approaches. Moreover, SCM provides a relation oriented approach and encourage cooperation and mutual interest, further attracting other parties to look forward for long term future relations (Katunzi and Qin, 2010). The foremost recommendation is an urgent need to spread the advantages of IT development tools, not only E-SCM, along with development of necessary IT skills that reduces the manpower and increase the productivity of existing human resource. This can be achieved through proper implementation of training facilities and system based practices by companies itself. With the increasing knowledge of computer skills, the implementation of further approaches like E-SCM becomes less cumbersome, and enterprises finds it easy to introduce a new technology, given existing assets are flexible to accommodate the changes.

Resistance of staff against any new technological intervention, working in e-business scenario can very well be a solution to that problem. Therefore, proper diffusion of technology inside the work culture is needed to enhance the e-readiness of organization, encourages top management for regular inflow of new ideas and technology adoption, and thereby further increase the diffusion of E-SCM for achieving maximum available benefits.

In order to acquire new knowledge, a firm should know the source and the path to find it, to assimilate back through in their own corporate structure. The advent of such technological advancement in a corporation also depends on the thrust of the business, on what kind of knowledge or system they want to look for. In that sense, a firm's absorptive capacity plays an important role in ascertain the proper diffusion of technologies like E-SCM.

\section{Limitations}

Like every research study, the current study also faced certain limitations, in light of which the results of the study may be used for any further purposes.

1. The current research is based only in one country Jordan. This limits the study from being universal in nature.

2. The sample considered for the study was small. Out of hundreds of small and medium enterprises, only 93 companies are selected.

\section{Direction For Future Research}

Due to the lack of accessibility, time and budgetary constraints, this study was confined only selected cities in Jordan. The same study may include more cities of different states. The researcher has taken only the managers of SMES as respondents. Future studies may include employees, customers, and business partners so that other factors may be well understood. Non-probability sampling method was chosen for this study and the sample size was determined keeping in mind previous studies. Future research can be undertaken by using different non-probability or probability sampling technique and may increase the sample size.

Future researchers may use other methods of data collection to empirically examine the relevance of the results of this study. The study focuses on E-SCM in SMES. This study can be extended by adding micro and large companies. Comparative studies between SMEs and large companies may result in better 
understanding of the adoption and implementation of electronic supply chain management in future where firms from different sizes will be compared.

\section{References}

[1]. Agrawal, N., \& Smith, S. A. (2009). Retail supply chain management. Springer US.

[2]. Al Bakri, A. (2013). An Overview of Information and Communication Technology (ICT) in Jordan: Review the Literature of Usage, Benefits and Barriers.

[3]. Al-Zu'bi, H. A. (2011). Organizational citizenship behavior and impacts on knowledge sharing: an empirical study. International business research, 4(3), 221.

[4]. Arend, R. J., \& Wisner, J. D. (2005). Small business and supply chain management: is there a fit?. Journal of Business Venturing, 20(3), 403-436.

[5]. Bayraktar, E., Demirbag, M., Koh, S. L., Tatoglu, E., \&Zaim, H. (2009). A causal analysis of the impact of information systems and supply chain management practices on operational performance: evidence from manufacturing SMEs in Turkey. International Journal of Production Economics, 122(1), 133-149.

[6]. Bharadwaj, A. S. (2000). A resource-based perspective on information technology capability and firm performance: an empirical investigation. MIS quarterly, 169-196.

[7]. Chapman*, R. L., \&Corso, M. (2005). From continuous improvement to collaborative innovation: the next challenge in supply chain management. Production planning \& control, 16(4), 339-344.

[8]. Dey, D., \&Nath, A. (2013). Study on key Issues and Critical Success Factors of e-Supply Chain Management in Health Care Services. International Journal of Advanced Computer Research, 3(1), 7-13.

[9]. Elahi, S., \&Hassanzadeh, A. (2009). A framework for evaluating electronic commerce adoption in Iranian companies. International Journal of Information Management, 29(1), 27-36.

[10]. Fatorachian, H., Shahidan, M., \&Kazemi, H. (2013, January). Role of Internet in Supply Chain Integration: Empirical Evidence from Manufacturing SMEs within the UK. In ECMLG2013-Proceedings For the 9th European Conference on Management Leadership and Governance: ECMLG 2013 (p. 66). Academic Conferences Limited.

[11]. Fatorachian, H., Shahidan, M., \&Kazemi, H. (2013, January). Role of Internet in Supply Chain Integration: Empirical Evidence From Manufacturing SMEs Within the UK. In ECMLG2013-Proceedings For the 9th European Conference on Management Leadership and Governance: ECMLG 2013 (p. 66). Academic Conferences Limited.

[12]. Kumanan, S., PrasannaVenkatesan, S., \&Prasanna Kumar, J. (2006). Optimisation of supply chain logistics network using random search techniques. International Journal of Logistics Systems and Management, 3(2), 252-266.

[13]. Lancioni, R. A., Smith, M. F., \&Oliva, T. A. (2000). The role of the Internet in supply chain management. Industrial Marketing Management, 29(1), 45-56.

[14]. Lankford, W. M. (2004). Supply chain management and the Internet. Online information review, 28(4), 301-305.

[15]. Lin, H. F. (2014). Understanding the determinants of electronic supply chain management system adoption: Using the technologyorganization-environment framework. Technological Forecasting and Social Change, 86, 80-92.

[16]. Mudholkar, P. K. (2012). Impact of e-business on corporate performance: with special reference to banking sector in Maharashtra.

[17]. Rahman, H. (Ed.). (2011). Cases on SMEs and Open Innovation: Applications and Investigations: Applications and Investigations. IGI Global.

[18]. Ratnasingam, P., \&Pavlou, P. A. (2004). Technology trust in internet-based interorganizational electronic commerce. The Social and Cognitive Impacts of E-commerce on Modern Organizations, 311.

[19]. Rosabeth Moss Kanter. (2001). Evolve!: Succeeding in the digital culture of tomorrow. Harvard Business Press.

[20]. Rosabeth Moss Kanter. (2001). Evolve!: Succeeding in the digital culture of tomorrow. Harvard Business Press.

[21]. Sahay, B. S. (2003). Supply chain collaboration: the key to value creation. Work study, 52(2), 76-83.

[22]. Sami El-Khasawneh, B. (2012). Challenges and remedies of manufacturing enterprises in developing countries: Jordan as a case study. Journal of Manufacturing Technology Management, 23(3), 328-350.

[23]. Seuring, S., \& Müller, M. (2008). From a literature review to a conceptual framework for sustainable supply chain management. Journal of cleaner production, 16(15), 1699-1710.

[24]. Trkman, P., \&Groznik, A. (2006). Measurement of supply chain integration benefits. Interdisciplinary Journal of Information, Knowledge, and Management, 1(38), 562.

[25]. Turban, E., Bolloju, N., \& Liang, T. P. (2011). Enterprise social networking: Opportunities, adoption, and risk mitigation. Journal of Organizational Computing and Electronic Commerce, 21(3), 202-220.

[26]. Utomo, H., \& Dodgson, M. (2001). Contributing factors to the diffusion of it within small and medium-sized firms in Indonesia. Journal of Global Information Technology Management, 4(2), 22-37.

[27]. Wojtkowski, W., \& Hardesty, J. C. (2001). Reality of Use and Nature of Change in Small Business: A Case Study in Inefficient. Annals of Cases on Information Technology Applications and Management in Organizations, 217.

[28]. Wymer, S. A., \& Regan, E. A. (2005). Factors influencing e- commerce adoption and use by small and medium businesses. Electronic Markets, 15(4), 438-453. 